\title{
Research and Exploration on the Teaching Innovation of the Advanced Manufacturing Technology Course
}

\author{
Fujian Yang a , Hongwang Zhao \\ Guilin University of Aerospace Technology, Guilin 541004, China \\ askeen2007@126.com
}

Keywords: Advanced manufacturing technology, Theory teaching, undergraduate education.

\begin{abstract}
In the face of the rapid development of advanced manufacturing technology, new knowledge and a wide range of contents. We need combined with the applied undergraduate education, pay more attention to the training of "applied" high-quality talents. Through the analysis of the training goal of this major and Analysis of the teaching objectives and contents of advanced manufacturing technology course. Put forward the teaching method of melting engineering in advanced manufacturing technology course and through the engineering of practice content teaching theory to the theoretical teaching. A single factor analysis method and comparison of two administrative classes on the degree of mastery of the curriculum and the achievement of the training objectives. The latter is obviously better than the former, It is proved that the effect of engineering teaching is better than the traditional theory course. A useful exploration in the teaching innovation of advanced manufacturing technology course.
\end{abstract}

\section{Introduction}

Advanced manufacturing technology is a new technology system that brings various changes to traditional manufacturing technology1, refers to the use of the technology such as microelectronic technology, automation technology and information technology which combined with the equipment and system produced by a combination of mechanical engineering technology, electronic technology, automation technology, information technology and other technologies. The whole process were involved of the product design, manufacturing, testing, management, sales, use, service and even recovery. Achieve high quality, high efficiency, low consumption, clean and flexible production ,so the manufacturing technology to improve the adaptability and competitiveness of dynamic and changeable product market and achieve the ideal economic effect. Through the study of this course, students can expand their knowledge level understanding the frontiers of manufacturing. But it's very theoretical, and these techniques seem very far away from us. The students' interest in learning is not high, the input is insufficient and the effect is poor. In order to improve the teaching effect, the objective of teaching and the content of the course are decomposed, Integrating the soft and hardware resources of the school, set up a number of practical production processes to show the main content of this course, Practice into the theoretical knowledge, Let the students start from the perceptual knowledge to learn the course, thus mobilizing the students' learning enthusiasm and improving the learning effect.

\section{The Construction of Teaching Objectives and Course Content in Advanced Manufacturing Technology}

\subsection{The Decomposition of the Content of Teaching Objectives}

Advanced manufacturing technology course is one of the core courses of mechanical specialty in undergraduate colleges and Universities. First, we need combed the contents of the course, and the knowledge points that the students must master in learning this course are clarified. It is divided into Teachers' knowledge points and self-study knowledge points, to clear the teaching objectives and methods of the knowledge point and to compile the teaching plan for the knowledge point. In the 
process of implementation, a positive understanding of the students' mastery of the knowledge point, the implementation of the scheme, and the teaching effect will be guaranteed. The general goal of the course is to make students understand the main advanced manufacturing technology and the advanced manufacturing system, and the understanding of the composition of advanced manufacturing system is beneficial to the development of "applied" high-quality engineering practice talents in the future. Learning advanced manufacturing processes2, such as precision and ultra precision machining, ultra high speed processing, special processing and rapid prototyping; Understanding modern design methods, such as computer aided design (CAD), 3D modeling design, finite element simulation design, reverse design and green design, etc.; Understand the latest automation technologies, such as computer aided process planning (CAPP), computer aided manufacturing (CAM), flexible manufacturing technology (FMS), computer integrated manufacturing system (CIMS), intelligent manufacturing system IMS, CNC machining technology and so on. The use of modern management technology, such as enterprise resource planning (ERP), product data management (PDM), just in time production (JIT), lean production (LP), and agile manufacturing (AM), etc.

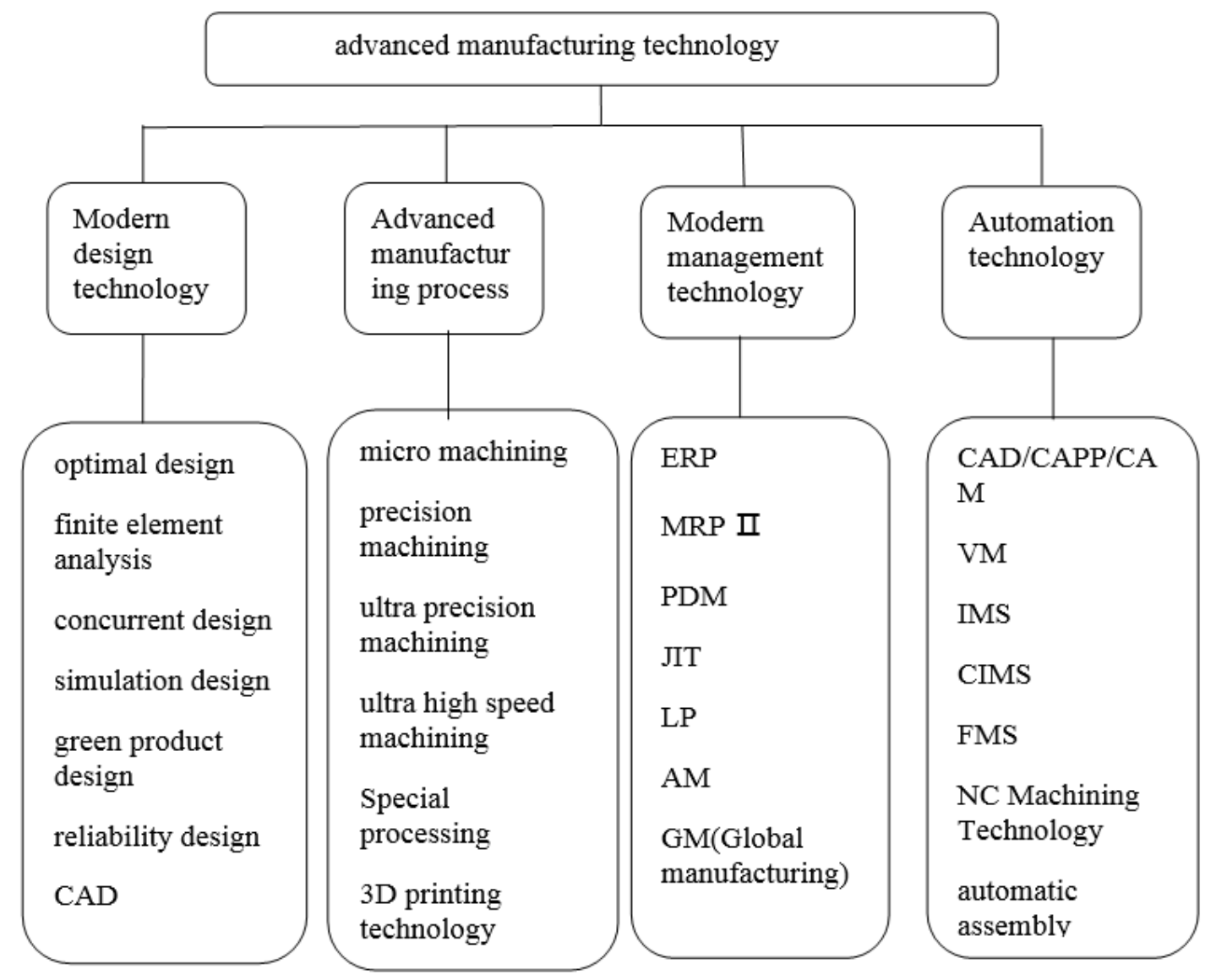

Fig. 1 The main contents of advanced manufacturing technology

\subsection{Practice in the Implementation of Theoretical Teaching Innovation}

The core of integrated teaching of advanced manufacturing technology course is the organic combination of theory teaching and practical teaching, The two must be taken into consideration in a large system, complete the teaching task systematically and realize the integration of teaching tasks. The theory teaching place is the same as the practice teaching field, and has enough practical teaching equipment to realize the integration of the teaching place3. The teacher can teach both the theory class and the practice course to realize the integration of the teacher's responsibilities. Carrying out the guiding ideology of education and teaching on the basis of quality education, ability as the standard and application as the main line, considering the current situation of students' cultural foundation, we should grasp the yardstick of teaching content in theory class, and adopt appropriate 
integrated implementation plan that can achieve knowledge goal, ability goal and quality goal; In the implementation of the integrated teaching course, the teachers need to correct their mistakes, affirm their achievements, sum up their experiences, and draw lessons from them, the integration of "project guidance, task driven" approach to the integration of curriculum content.

Engineering practice one: Select the middle complex motor spindle, the reverse engineering is realized with the help of three coordinate measuring instrument and three coordinate scanner. Using modern design technology, the product is optimized, reliability design, green design, and finite element simulation is carried out. Use automation technology and advanced manufacturing technology to process the designed products; use modern management technology ERP to manage.

Engineering practice two: The modern design is realized with UG, PRO-E and so on, and making use of CAPP/CAE/CAM for simulation manufacturing. Finally, the modern design, the virtual manufacturing and simulation, the numerical control complex machining technology are applied to the CNC machine tools.

Engineering practice three: The modern design is realized with UG and other three dimensional software, and the combination of the modern design idea and the rapid prototyping technology is realized by combining the 3D printer4. 3D printing and manufacturing (added material manufacturing) is a new manufacturing process that directly outputs (Manufacturing) physical products through computer product design, and then through 3D printing equipment. The technology promotes the manufacturing industry to enter the stage of personalized production, and is the best solution for making customized manufacturing. At the same time, the 3D printing process has the shortest process, so once it overcomes the limitations of the slow processing speed at present, It will become a real agile manufacturing approach, in line with the pursuit of agility in advanced manufacturing industry.

The course involves many advanced equipment5, and different equipment groups will be arranged in different locations, such as the area of numerical control vehicle, CNC milling area, multi axis machining area, special processing area and modern measurement area. The distribution of the places is very wide, and the micro electric classroom can be added in every practical training place, equipped with projector, computer, etc. It is used to teach relevant theoretical knowledge in time and to realize the integration of theoretical and practical teaching fields. The integrated teaching field is as close to the actual production practice as possible to better train the students' ability of engineering management and comprehensive evaluation.

\subsection{The Effect of Implementing Innovative Teaching}

Carry out a pilot project for 40 students majored in machinery, we analyzed The examination results after the final examination. Compared with the students who did not implement the practical course, The result of the comparison of students' score distribution is shown in Figure 2. The result shows that after the implementation of the practical curriculum reform, the students' overall achievement has been improved obviously. After the course of the course and the end of the course examination, a number of questionnaires were organized, Understanding the influence and effect of each knowledge point on the students according to the practical teaching of the curriculum. Two aspects such as the satisfaction of the curriculum and the help of the practice on the course are investigated. Through the analysis and statistics of the questionnaire, The results show that most of the students hold a supportive attitude towards practical teaching. Meanwhile, most students think that implementing practice teaching is helpful for course learning. 


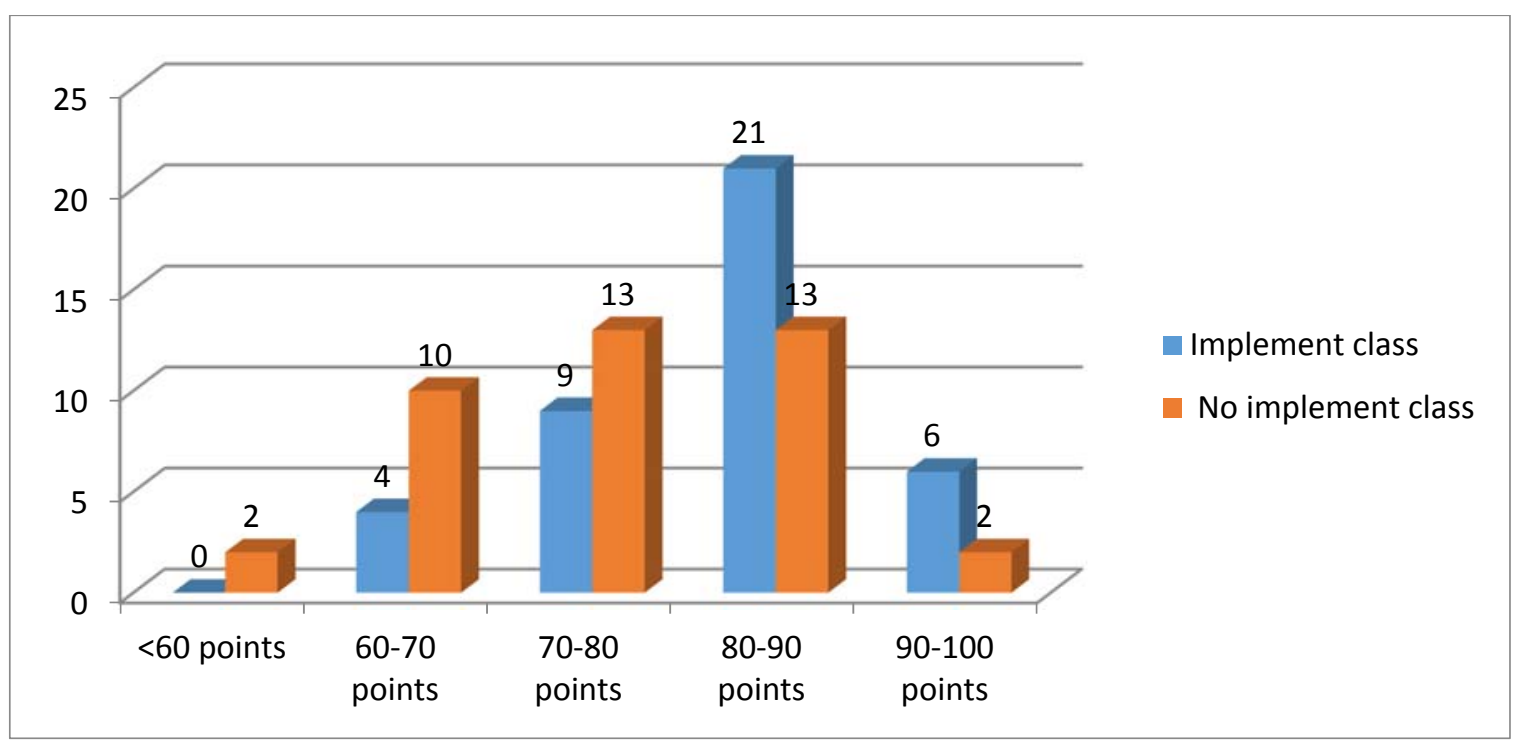

Fig. 2 The comparison between the implementation of practical teaching and the students' test results in the non practical class

\section{Summary}

Advanced manufacturing technology is a summary of the knowledge of a multi interdisciplinary subject, In the course of teaching, the teaching content, teaching means and teaching methods are constantly improved on the basis of the characteristics of the teaching content of advanced manufacturing technology course. Stimulate students' self-learning ability, improve students' ability to analyze problems, solve problems and comprehensive application ability. We should enhance students' engineering literacy, engineering practice ability and innovation and entrepreneurship awareness so as to adapt to the training objectives of mechanical engineering and better adapt to future work needs.

\section{Acknowledgments}

This work is carried out with the support of the research project of teaching reform of Vocational Education in Guangxi in 2016. The construction and practice of the curriculum system of automobile inspection and maintenance specialty based on the cultivation of post professional ability (NO.GXGZJG2016A058).

\section{References}

[1]. Yanhua Sun. advanced manufacturing technology [M]. Beijing:Electronic Industry Press,2015,p.2-8

[2]. Xingsheng Bao, Fuling Xu, Yongjie Cao. The implementation of the integrated teaching method of advanced manufacturing technology course[J]. Scientific and technological information.Vol.11 2017 , p.140-142

[3]. Lingjiang Ouyang, Jian Zhang. The present situation and reform of advanced manufacturing technology course in Higher Vocational Education[J]. Research on education and teaching. Vol.11(7),2015.p.41-43.

[4]. Jinming Guo, Like Yuan, Qiquan Yang, Ge Wang. A deep analysis of the development trend of advanced manufacturing technology[J]. Research on science and technology management. Vol.13,2015,p.262-263 